CARLES MÉNDEZ LLOPIS

UNIVERSIDAD AUTÓNOMA DE CIUDAD JUÁREZ

CIUDAD JUÁREZ, MÉXICO

CMENDEZLLOPIS@GMAIL.COM

Fecha de recepción: 26/02/2019

Fecha de aceptación: 09/05/2019

Cómo citar: Méndez Lopis, C. (2019) Gráfica

caminante: el tatuaje como relato y el cuerpo

como libro.

RChD: creación y pensamiento, 4(6), 1-11

DOI: $10.5354 / 0719-837 \times .2019 .52417$

Revista Chilena de Diseño,

RChD: creación y pensamiento

Universidad de Chile

2019, 4(6)

http://rchd.uchile.cl

\section{Gráfica caminante: el tatuaje como relato y el cuerpo como libro}

Walking graphics: The Tattoo as a Story and the Body as a Book

Resumen. El presente texto sigue la tradición de pensadores que ubican al cuerpo como problemática en el campo estético y nos obligan a concentrarnos en sus diferentes dimensiones y manifestaciones, donde la corporeidad implique vivencia tanto del hacer como del sentir y el pensar. Bajo esta perspectiva nos proponemos abordar las potencialidades del tatuaje como relato con el que representamos nuestra interioridad gráficamente sobre nuestra misma superficie, con la finalidad de establecer analogías con el concepto de edición. Esta suerte de gráfica viva será analizada a través de un acercamiento fenomenológico de los cuerpos diseñados, que se encamine a establecer relaciones entre la carne dibujada y la edición de un libro, a fin de posibilitar poéticamente la idea de cuerpo como libro, donde significado y significante formen parte del mismo tejido, donde el relato de la experiencia vivida ofrezca una suerte de presencia en la piel.

Palabras clave: cuerpo, diseño, gráfica viva, tatuaje.

\begin{abstract}
The present text follows the tradition of thinkers who place the body as problematic in the aesthetic field and force us to concentrate on its different dimensions and manifestations, where corporeity implies experience of doing as well as feeling and thinking. Under this perspective we propose to approach the potentialities of the tattoo as a story with which we represent our interiority graphically on our same surface, in order to establish analogies with the concept of editing. This kind of living graphic will be analyzed through a phenomenological approach of the designed bodies, which is directed to establish relationships between the drawn flesh and the edition of a book, in order to enable poetically the idea of body as a book, where meaning and significant are part of the same tissue, where the story of lived experience offers a kind of presence on the skin.
\end{abstract}

Keywords: body, design, living graphics, tattoo. 
Introducción: la vida encarnada del cuerpo como generador de sentido. Nuestro contexto es el cuerpo, es el que nos ofrece el mundo -y viceversa-, estamos allí y aquí con él. Más que pertenecernos, el cuerpo supone nuestro primer ambiente de acercamiento al mundo, compone un "sistema de sistemas consagrado a la inspección de un mundo, capaz de salvar las distancias, de penetrar el porvenir perceptivo" (Merleau-Ponty, 2006, pp.75-76). Somos el mundo y lo recuperamos en nuestra experiencia, y para esta recuperación, diseñar nuestro cuerpo supone una herramienta significante: nuestro cuerpo "diseñado", ilustrado o escrito con el tatuaje refleja el entorno, porque supone materializar nuestro sentir el afuera y exponerlo al otro. Es una significación y enunciación en el soporte del mismo discurso, un sobrediscurso que "se comporta como marca, impronta, sello en tanto que registro de significación” (Ferrada, 2014, p.131).

Al ubicar al cuerpo como problemática en el campo estético a través del tatuaje, debemos revelarlo como sensibilidad que nos inserta en el mundo y que intensifica posibilidades de sentido en lo cotidiano. Sin embargo, en esta tesitura ¿qué implicaría considerarlo como generador de sentido y como ente en continua relación con el mundo? En primer lugar, implicaría atestiguarlo como corposfera, es decir, atender al cuerpo fenomenológicamente como un complejo semiótico amplísimo que "abarcaría todos los signos, códigos y procesos de significación en los que, de modos diversos, el cuerpo está presente, actúa, significa" (Finol, 2014, p.163). A partir de este enfoque, tomaré el cuerpo como un lugar en el que se originan un conjunto de lenguajes que se actualizan y modifican constantemente, donde la piel sirve precisamente de marco de semiotización y de límite y frontera al construir nuestra corporeidad, nuestro vivir en el hacer, en el sentir y en el pensar (Carvajal, 2014). Esta posición fenomenológica, claro, sentencia al cuerpo a un proceso de interacción con la realidad, lo sitúa como primer contexto en el que nos construimos (en su tiempo y espacio), es decir, un contexto de re-flexión sobre la mismidad y la construcción de subjetividades que solo puede tomar conciencia de sí a partir de nuestra condición sintiente del mundo. Sin embargo, y aunque no será este el objeto del presente texto, habría que matizar que somos herederos aún del pensamiento cartesiano donde "el cuerpo es un objeto objetivable, una res cogitans, donde la dimensión corporal queda reducida a la materia" (Ferrada, 2014, p.41). En este sentido, resulta difícil eludir la etapa de narcisismo dominante en el escenario actual, donde esta interacción con la realidad se ve sometida a la objetualización del cuerpo como consumo cultural en el que convergen los más dispares intereses económicos. El cuerpo se nos presenta como objeto -y objetivo- aparente, una cosa entre las muchas que lo rodean, un algo que nos pertenece, $y$ quizás por esto -aunque nos desviemos ligeramente-, es inevitable dejar de atender el cuerpo -los cuerpos- como centro neurálgico de la economía e ideología contemporáneas, pues al resituarlo como producto mercantil también estamos considerando su producción de sentido en la actualidad.

Así, si en este sentido el cuerpo es en-carnación de un lugar y un tiempo, se acodará siempre en cierta mirada que configura su experiencia que produce sentido-en-continuidad, y será por tanto en interacción con el mundo, en el contacto con un "otro", que se dibujarán los contornos de su universo, de su realidad simbólica. Es decir, si el cuerpo es un lugar de contacto, la piel fungirá de frontera y separación entre lo que es él y lo demás, y a su vez lo integrará 
en esa realidad. Actuar sobre el cuerpo -en su piel- modificará a la vez su alma (Le Breton, 2002), y a la inversa, pensamos que también cualquier transformación interna se verá exteriorizada de diversa forma sobre ese cuerpo, y que el tatuaje, de algún modo, más que postular ese cuerpo como territorio de consumo y rentabilidad -que también-, lo concreta como este eje de conexión que decimos: un lugar en el que entran y salen las significaciones individuales y colectivas. Una borrosa línea cuya diferencia puede aterrizarse en la afirmación de Esposito (2016) cuando menciona que "Yo no tengo, sino que soy mi cuerpo" (pp.115-116), desconectándolo de objeto a ser poseído para verificarlo como sujeto que es sujetado en el acontecimiento del mundo, en el que se vacían y externan las influencias y afectaciones de ese afuera a través del cuerpo que se relaciona subyugado a sus acciones.

En consecuencia, por su condición de construcción simbólica, el cuerpo es una ficción -y no una realidad en sí- que nos permite operar con y en el entorno. Asumir la tesis de Merleau-Ponty (1993) es dejar de regirnos solo por la organicidad y renunciar a evitar las afectaciones, e inscribir al cuerpo como "nuestro medio general de poseer el mundo". Un discurso que admite conjeturar los cuerpos tatuados como operaciones editoriales que visibilizan sus relaciones con el libro en sus conexiones con el mundo, y lo posiciona como lugar en el que el lenguaje, escritura, espacio y pensamiento se encuentran para conformar aperturas de sentido. De este modo, ambos se significan gráficamente como espacios expresivos y tejidos que re-conocen el mundo y que disponen el recuerdo y la vivencia en un afuera para aumentar el espesor de la realidad. El hecho de atribuirle a la gráfica expuesta sobre el cuerpo su necesidad de haber sido vivida, la aproximará a su condensación simbólica, a los discursos y políticas de nuestro propio vivir, ayudándonos a conquistar, de algún modo, el relato ubicado en un afuera.

\section{La membrana ilustrada: cuando lo más profundo es la piel}

La piel tatuada no es un área cualquiera, su profundidad se significa precisamente en esa idea de superficialidad, pues sobre ella surge gráficamente, se manifiesta, el espesor del cuerpo: su relato. Todavía en el plano poético: ver las cosas desde una piel dibujada supone hacer del tacto ${ }^{1}$ el sentido que rija nuestra relación con el mundo, una historia de la memoria que implique al cuerpo como lugar de pensamiento y al tatuaje como forma de manifestarlo. El tatuaje subraya aquello que ya Richir (2015) anunciaba cuando argumenta que "no hay pensamiento sin cuerpo" (p.33), pues esa relación inextricable sale a la superficie. Así, si bien desde el tatuaje podemos hablar de la piel como envoltorio, tanto como una estructura relacional con el mundo y con nuestra individualidad a la vez - hacia afuera y hacia un adentro-, también podemos comprenderla como frontera que organiza y regula ese cuerpo respecto a otros. Una membrana que "establece acercamientos, permite aproximaciones entre actores, espacios y tiempos, y, desde allí, intercambios que pueden ser más o menos fluidos o más o menos tensos" (Finol, 2014, p.158). Es decir, además de establecer límites, tatuarse también permite que una substancia devenga otra a través de ella, proponiéndose como lugar de transición entre el adentro y el afuera, entre la vivencia y el relato. Por ello, esta vivencia contextual del cuerpo de la que hablamos toma la membrana ilustrada como borde semiótico, estableciéndose como territorio regulador de la comunicación y el intercambio de sentidos. Ilustrar sobre la piel es, de algún modo, escribir una biografía.
1. Este sentido del tacto excede la condición tradicional, pues: "Tocar no implica necesariamente el contacto táctil de los cuerpos, sino que es un toque directo al interior del cuerpo, al ser sensible, desde el alma" (Ferrada, 2014, p.128). 
La piel define nuestra corporeidad, "expone e interioriza a la vez el tacto del sentido y del sentir" (Ferrada, 2014, p.101), es nuestra vía de contaminación del mundo en el que nos espejamos como sujetos al igual que un libro abierto: implica una contienda lingüística. Así, el tatuaje hace (re)conocer la piel como límite y margen, como horizonte entre lo pensado y sentido, y lo expresado respecto ese mundo fuera y dentro del cuerpo. Si la piel corpora nuestra realidad, el tatuaje in-corpora nuestras vivencias sobre aquella, pues al moldear nuestro cuerpo la intervenimos y alteramos en orden de exponer y significar nuestro ser al mundo, para interactuar con ese universo ajeno a nosotros. No hace falta acercarnos mucho a esta contigüidad semiótica que presentamos para observar las analogías y similitudes con el ámbito editorial. Si se entiende entonces que el cuerpo habita, así como es habitado, al marcar su piel, al diseñar sobre ella, abrimos un territorio borroso de márgenes desdibujados en los que emergen las profundidades de nuestra relación con el habitar el mundo. Interpretar en este sentido la superficie corporal, como leer un libro, asume un desciframiento de la alteración -lo tatuado o lo escrito-, pues se entienden las especificidades de cada topografía, en distinción y multiplicidad (en el hacia afuera y en el hacia adentro), por lo que habrá que comprender que cada cosmogonía expuesta habrá sido cimentada sobre la relación e intercambio simbólico del individuo. Con el tatuaje, la piel se subraya más allá de "frontera o valla entre la interioridad del cuerpo y la exterioridad circundante, pues la piel como superficie genera un flujo orgánico y, al mismo tiempo, un intercambio social, clave en la vida de cada sujeto" (Rossi, 2011, p.18). Como decimos, la piel es conexión y, por tanto, así como por extensión entendemos el libro como artefacto que material o digitalmente plasma y almacena pensamientos, el cuerpo tatuado se impone como dispositivo cultural y simbólico que proyecta su propio discurso al espacio social. El tatuaje implica por tanto el uso de la piel para politizar el cuerpo desde la autonomía del individuo, un gesto expresivo que recupera su alrededor (Merleau-Ponty, 2006) al entender que el "cuerpo es el mundo y el mundo es en la piel tatuada" (Garrido, 2010, p.11), pues después de ingresar a ese cuerpo, el mundo quedó en esa piel registrado.

\section{La gráfica viva / El diseño caminante}

Los ejemplos que siguen son resultado de identificar esta piel ilustrada como medio de expresión que recupera el mundo externo e interno, ejemplos que subrayan al soporte tanto como discurso como libro -autobiográfico- en el que se escribe sobre sí mismo. De este modo, los cuerpos que anotaremos a continuación "soportan" información proveniente de la actividad intelectual de los individuos, que hacen servir sus mismos cuerpos como registro y documentación de sucesos, experiencias, acontecimientos vividos que pasan a ser traducidos de forma más duradera. Los cuerpos se cargan entonces de memoria resguardando y cobijando las singularidades subjetivas a través del tatuaje, de una gráfica que se materializará en dichos cuerpos para sujetarlos a su sujeto. De este modo, presento a los cuerpos diseñados -o la gráfica corporal- como una suerte de encarnación editorial, que presupone una edición o posproducción del propio cuerpo que encamina relaciones a partir de la producción y circulación de la carne dibujada con las cosas: "anulando límites objetuales, haciéndose accesible y portátil, conquistando los elementos cotidianos que coexisten en nuestro entorno, transformándose en una gráfica viva" (Méndez, 2010, p.189). Sabemos que muchas y diversas culturas poseen una larga 

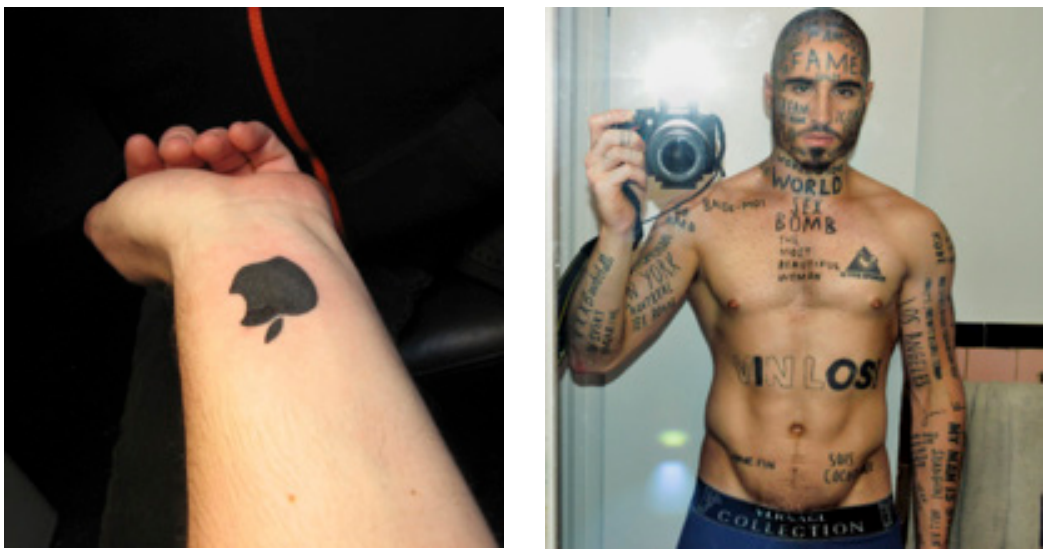

historia y relaciones solemnes con el tatuaje, una gráfica que si bien en el mundo contemporáneo ha visto modificado -y en ocasiones, aligerado- su principio ritualista ancestral, todavía posee una poderosa carga política. Es decir, aunque en gran parte de las geografías -sobre todo, primermundistasya no sea recordado su carácter sanador o su asociación a determinado prestigio social como en la antigüedad, su práctica no cesa de documentar las relaciones del cuerpo y en el cuerpo con su entorno y consigo mismo. Aún en su vertiente "decorativa" -refiriéndome a su propósito formal- o dispuesto a los establecimientos de tendencias pasajeras, y carente de sentido ancestral -entendamos original, si eso es posible-; aún formateado como marca de la sociedad de consumo y ejercicio ornamental edificado desde la desvinculación de ese "sentir el sentido", incluso así, no podemos desprender la "moda o tendencia" de su sincronía como documento histórico -estético y sociológico- que absorbe los sentidos y sensibilidades de un tiempo concreto.

Si observamos las figuras 1 y 2 , nos damos cuenta precisamente que remarcan este sentido de pertenencia a la industria cultural en el que marcas, por un lado, y mensajes vinculados a la objetivación del cuerpo, exponen al tatuaje como parte constructiva del sujeto, con la que se identifican, exponen su autenticidad o manifiestan su rebeldía e intercambian sus experiencias o sus recuerdos. Siguiendo esta línea, Carvajal (2014) anota que "el consumo cultural, en este sentido, se convierte en producción simbólica, es un acto expresivo y creativo en el que el sujeto se piensa a sí mismo y en relación con los demás toda la idea de comunicación como interacción" (p.26).

Al concebir la piel como un espacio para textos o discursos de algún tipo, los fines del tatuaje -sean expresivos, estéticos, rituales, terapéuticos, incluso punitivos, entre muchos otros- afirman tanto una identidad como cierta condena social al cuerpo portador ${ }^{2}$. Al respecto conviene revisar a Sastre (2011) cuando nos recuerda que:
Figura 1. Tatuaje de la famosa manzana de la compañía informática Apple en la muñeca. Figura 2. Vincent Langlois (Vin Los), modelo canadiense que tatuó su cuerpo con diversos mensajes a fin de corporizar la cultura pop y entrar en el mundo de la fama.

2. Conocido es el acercamiento e interés de los sectores marginales del siglo XIX y principios de $X X$-sobre todo en prisión- por este diseño corporal que acabó erigiendo una visión negativa y políticamente incorrecta de dicha marca entre los ciudadanos. El tatuaje se movía por los márgenes por lo que su exposición implicaba una denominación de origen marginal (García y Guzmán, s.f.), pero aunque aún persisten las opiniones moralizantes sobre el tatuaje, aquellas que equiparan cuerpo-tatuado a conductas ilícitas o antisociales, han ido progresivamente descendiendo. Garrido (2010) anota que ya la incursión del tatuaje a Occidente fue desde "una práctica marginal: marineros, presos, prófugos y condenados, se marcan la piel para encarnar el estigma y esa mirada aún perdura. Durante el siglo XX la práctica del tatuaje también se vinculó al ejercicio del horror: Auschwitz es el ejemplo paradigmático, donde los tatuajes tomaban la forma de un número identificatorio" (p.3). De hecho, su atribución periférica y "barbárica” sigue marcando los sistemas institucionales -aunque por ejemplo haya sido absorbido por los mecanismos de la moda-, y es generalmente considerada una práctica nociva que debe alejarse de los circuitos oficiales.

El cuerpo se percibe como testimonio de vida, del modo en que lo haría un diario. El cuerpo se percibe como un texto que habla del sujeto, de lo significativo en su vida, de aquello a lo que el sujeto da relevancia, de lo que tiene importancia: es un texto mediante el cual habla de sí mismo a otros. El cuerpo tatuado recrea, trae al presente y materializa de manera permanente aspectos del sujeto, los explicita, evidencia su filosofía de vida, 
Figura 3. Tatuaje con número identificatorio de superviviente, Ceremonia del Día Internacional del Recuerdo del Holocausto en la plaza Raoul Wallenberg, Estocolmo en el año 2013.

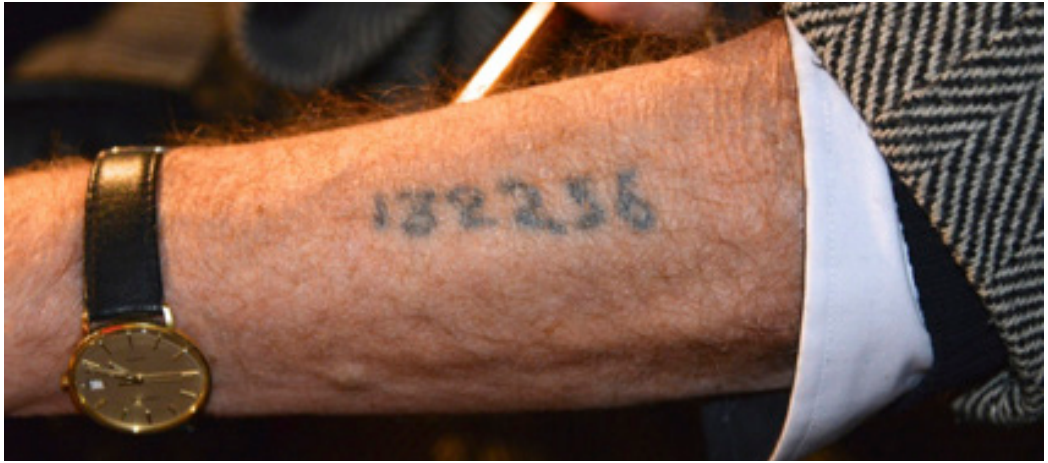

sus compromisos existenciales o la ausencia de los mismos y asegura un sentido de trascendencia ontológica. El cuerpo es su identidad subjetiva. (p.184).

Por estas razones, reclamar un discurso por la vía del cuerpo, así como lo hace un texto por la vía del códice, da carne a una existencia despreciada, a una experiencia vaciada y, por tanto, a una resistencia y conquista del propio organismo que afirma la identidad del individuo.

De este modo, el tatuaje propone una nueva configuración del individuo, "una marca que vela la primera identidad del sujeto o que la completa de manera imaginaria" ya que, al significarlo a través del signo, aquello "que no se pudo inscribir en lo simbólico; lo que no se puede poner en palabras, lo que no se puede elaborar desde el discurso, se pone en el cuerpo" (Foos, 2012, pp.28-29). Ahora, en el s.XXI, se entiende al menos su polisemia, tanto en su ámbito privado como su inserción pública: se la considera una gráfica viva y caminante, que es ahora piel y que tanto mira como es punto de las miradas. Aunque todavía no estamos exentos de apriorismos y prejuicios, pues este registro aun conlleva penalizaciones culturales, la mayor parte de las veces por la iconoclastia que significa "mancillar el cuerpo", como si desconfiáramos de las imágenes solo por el desplazamiento y el deslizamiento interpretativo que provocan, o por estar en un territorio -el cuerpo-, inusitado, que no es el suyo. Sin embargo, esta representación no es un simulacro o

reemplazo de la cosa original; de hecho, no se refiere a una cosa: o es la presentación de lo que no se resume en una presencia dada o consumada (o dada consumada), o es la puesta en presencia de una realidad (o forma) inteligible por la mediación formal de una realidad sensible. (Nancy, 2007, p.30)

De hecho, en la figura 3 se puede observar la doble violencia de incidir sobre un cuerpo a través del tatuaje "identificatorio" en los campos de concentración nazis: por un lado, inscribir sobre cuerpo ajeno la memoria que se quiere evidenciar sobre el mismo, una que no le pertenece, pero que le va a ser grabada; $y$, por otro lado, el contenido simbólico del numeral asignado a los cuerpos sin nombre, y por tanto, sin vida propia. De esta forma, como digo, el cuerpo es conquistado, pero no por el sujeto que lo habita sino por quien le ha usurpado el mundo que le había sido dado. 
En cualquier caso, del mismo modo que el texto sobre la página, el tatuaje desea preservar algo, en principio para siempre -que el cuerpo aguante-, sea una imagen, una idea, un recuerdo o incluso un deseo, escrito para no ser olvidado, en un soporte que mantenga su valor. En el tatuaje existe una recuperación del mundo por parte del sujeto que nos hace pensarlo como inscripción de la memoria, como huella objetivada en el cuerpo, tallada para conmemorar aquello que no está, para ser presencia de una ausencia (Garrido, 2010). Un recuerdo que revela su significancia al dimensionar visualmente -e incluso verbalmente- el objeto de deseo y al involucrar al cuerpo voluntariamente para su permanente ingreso al mundo; rememoración que, finalmente, se "hace piel" a través de las imágenes, que se imbrican con aquella para incorporarla al plano del lenguaje. Eso sí, no es cualquier dibujo sobre una hoja de papel, es una gráfica viva, móvil y cambiante en una planicie que se niega a callar sin atestiguar y relatar su historia, y que manifiesta tanto una huella escrita en el cuerpo-materia como una impronta afectiva en el alma. El cuerpo como libro funciona de herramienta mnemotécnica que "opera siguiendo las huellas de la imaginación" (Ricoeur, 2000, p.21). Como vemos en la figura 4, el cuerpo sirve incluso de recordatorio, de soporte conmemorativo que ofrece en la superficie de la persona la narración de sus crónicas y memorias. De este modo, el tatuaje podremos resumirlo en una vinculación, en una voluntad de rememoración de una afección que queda documentada en la piel; pero más allá de esto, es una grafía que relata desde la carne, ya que vuelve la piel un lugar de acontecimientos y construcciones simbólicas, asignadas al libro tradicionalmente como transmisor cultural, y alejadas ahora de la dominación de otros canales de comunicación.

El cuerpo es (re)apropiado a través de la gráfica, que lo activa desde aquella significación que se niega a ser solo "piel sin marcar" para ubicar su relato dentro de la circulación pública. De este modo, reclama ser visto como panóptico invertido (Garrido, 2010) y se metaforiza en posesión del mundo, comunicándolo mientras lo habita, lo recuerda y lo significa. Es decir, el tatuaje propone la carne como unidad discursiva atípica, se alza como voz indómita al curso oficial para dar lugar a la expresión de sentimientos, ideas y recuerdos. En analogía al mundo editorial, cuando alguien se llena la piel de dibujos, como anuncian Corci y Mayer (1998), ofrece una discontinuidad similar a las palabras, pues solo cuando sumamos los fragmentos que el cuerpo soporta comprendemos que este es un lugar común para textos complejos provenientes de diferentes imaginarios y fuentes.

Un rompecabezas que nos obliga a especular con la continuidad -ahora sí- entre pensamiento y cuerpo acontecida gracias al tatuaje, un dispositivo expuesto en un espacio común que sirve para la coexistencia de ambas sustancias: aquella que promete y la que posibilita narrarse a sí mismo. Como vemos, del mismo modo que el libro, supone una narración en expansión que se extiende desde la piel para incentivar una sociabilización del relato que organice de otros modos la "distribución de conocimientos, creencias, convenciones, la comprensión de imágenes, de metáforas, la elaboración y la confrontación de razonamientos, la transmisión de emociones y de sentimientos, entre otros" (Candau, 2006, p.15). Atentos a esta producción gráfica de y en los cuerpos que se narran para los otros, entraremos en las diversas lecturas y vinculaciones que se apuntalan desde estas historias caminantes instaladas como una memoria persistente. El libro, de muchas formas posibles, es no ceder al olvido,

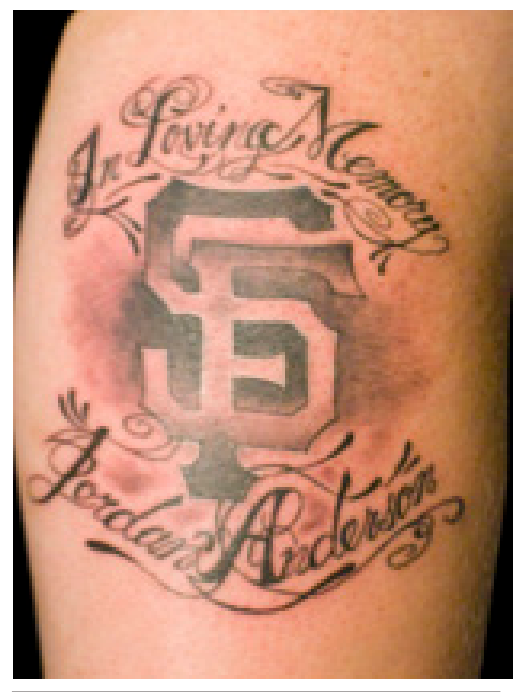

Figura 4. Fotografía del usuario Mez Love, tatuaje-recuerdo (SF Memorial). 
Figura 5. Fotografía de Rick Genest "Zombie Boy" en Londres en octubre de 2016 , en el lanzamiento de Platform 15, nueva atracción del terror de Thorpe Park para la celebración de Halloween. "Zombie Boy" se tatúa en su superficie precisamente el interior, lo que es adentro es afuera y viceversa.

3. Este huir y guarecerse del olvido no ha de significar necesariamente una traducción o transducción fiel y verídica de aquello que sirvió para la figuración. Por el contrario, la individualidad y la subjetividad de las experiencias dejan paso a la imaginación y el deseo, por lo que el tatuaje es una expresión y dotación de sentido de un mundo -ni siquiera todos los mundos posibles-, y además, en su polisemia sirve a diversos trazados de la narración y en su metáfora a la apertura de su sentido.

4. Con la finalidad de plantear de forma exploratoria una suerte de posibilidades metafóricas que sugieran ciertas similitudes entre las relaciones del tatuaje con el cuerpo y las del texto con el libro, trabajo sobre dicho concepto sin abordar el amplísimo universo de especificidades posibles. Por ello, el presente acercamiento panorámico pecto más que a desarrollar aquí casos definidos.

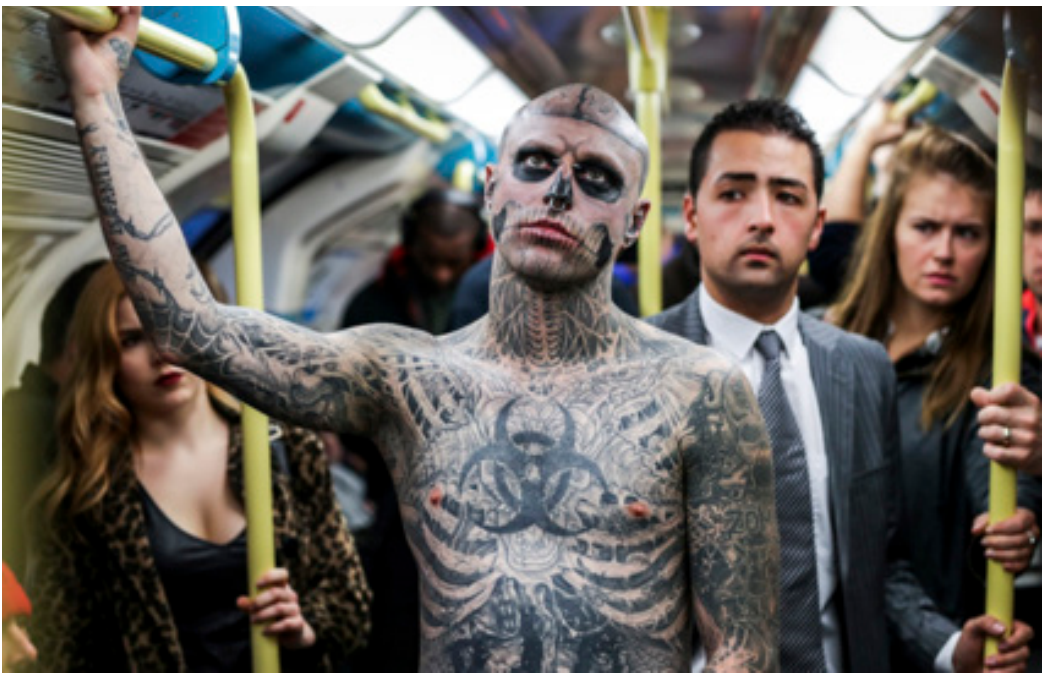

es resistirse a una fuerza natural -actualmente impuesta con barbarismo económico e ideológico-, tomar el recuerdo y la imaginación como materia prima que trae al ahora aquello ausente. Esta ausencia se autorreferencia constantemente en los cuerpos tatuados, como ilusión de sí misma, enunciando una "verdad subjetiva", una "ficción de realidad" para completarse3.

La materialidad de la gráfica sobre el cuerpo posibilita la vinculación del espacio y el objeto de diseño, no precisamente en la curvatura de las superficies (objetos), sino en la de los sujetos/superficies. Ni el cuerpo, ni la piel, ni siquiera el tatuaje, son una misma cosa que pueda definirse en su absoluto, pues sus diversos lenguajes y simbologías dependen de estados y contextos, de diferentes ranuras y construcciones ${ }^{4}$. El cuerpo, por ejemplo, no solo responde a un soporte de sentido, en ocasiones es un dentro donde nos proyectamos, $y$ otras veces un fuera que regula nuestras relaciones, así "el cuerpo significante no cesa de intercambiarse dentro y fuera, de abolir la extensión en un único órganon del signo: ahí donde se forma y de donde toma forma el sentido" (Nancy, 2003, p.54). El caso de Rick Genest (Zombie Boy, figura 5) ejemplifica a la perfección esta idea de "lo es afuera es adentro y viceversa" en el tatuaje, para quien la piel es un territorio compartido con el interior del sujeto, que en su cuerpo da forma a detalles anatómicos -cerebro, huesos y vísceras, entre otros- para poner a la vista la leyenda del mundo material interno. Con Zombie Boy visualizamos que el tatuaje es en el cuerpo, ni fuera ni dentro. No es del todo interior, pero sin aquello no sería superficie, pues es el recuerdo el que ingresa de nuevo a través de la configuración visual sobre él, como eco de la voz interior. En él, fuera y dentro coexisten, por lo que "el tatuaje, entonces, no es una parte de sí mismo: es una síntesis del sí mismo, al identificar de manera explícita y objetiva aspectos de la subjetividad" (Sastre, 2011, p.187).

El tatuaje es grafía y enunciación a la vez del propio discurso -como historia y narración, como relato y mediación-, como forma posible entre todas las permitidas, todo lo fidedignamente próxima a la voz del sentido, esa que ahora (re)significa la piel. Al figurar la ficción del relato, el tatuaje pliega, despliega y repliega más allá del trazado, como una aparición que se relaciona con la memoria de lo aparecido. Finalmente, le dota de narración a cualquier 
acontecimiento u objeto de la vida de ese cuerpo que, ahora, se opone y resiste, desplace ese peligro de ser olvidado: “...el tatuaje es el límite entre la piel y el mundo, entre la existencia individual y colectiva. No es interior ni exterior, sino el lugar por el que el cuerpo expreso -como gesto comunicantey desde el cual la significación ocurre con los otros" (Garrido, 2010, pp.15-16). Una imagen-recuerdo de uno para el resto.

Así como el relato otorga densidad a un libro, el tatuaje densifica el cuerpo, y así como el libro son sus páginas entintadas, en la piel tatuada la gráfica es indistinguible del organismo que lo porta que, a su vez, elabora el discurso del sujeto en su caminar, resistente como todo recuerdo. Esta tinta permanente sobre la superficie del cuerpo expande al individuo "fuera de sí" pero a través de él mismo, exhibe su construcción y proceso simbólico en sus circunstancias de vida (diversas y complejas): "La experiencia de los sujetos que se tatúan presenta al cuerpo como posibilidad que puede abrir el espacio para contemplar otras facetas relacionadas: el cuerpo-diálogo, el cuerpo-presencia, el cuerpo-testimonio, el cuerpo-comunión con, el cuerpo-integración con el contexto." (Sastre, 2011, p.189). Al ver el brazo incompleto de Daniel Crane (figura 6) con el mensaje tatuado: "Faith and trust in what we cannot see" (Fe y confianza en aquello que no podemos ver) comprendemos que en el ámbito de la natación esa amputación ha de ser compensada simbólicamente, y el mensaje indemniza metafóricamente la ausencia física del miembro. El brazo, de alguna manera, ha de estar metafóricamente completo en algún punto. Así, este diseño caminante, esta ilustración viva sobre los cuerpos, formaliza el ruido del discurso frente al silencio de la desnudez natural. Fomenta el lenguaje articulado que activa el cuerpo -en este caso, parte de él-y lo pone en circulación (Foos, 2012), donde la interioridad sensible del sujeto se hace consciente y visible, donde reconoce su estar en el mundo a través del cuerpo mostrando cómo viven las cosas y las experiencias en nosotros por medio de la piel, cómo las encarnamos.

\section{Conclusiones: cuerpos escritos y relatos encarnados}

Recapitulando, he presentado una panorámica que concibe la corporeidad como problemática del campo estético a fin de proponer el cuerpo diseñado como ejemplo de edición, como cuerpo editado/editable en el que idea y forma -pensamiento y superficie- se concentran en la piel a través del tatuaje. Una potencialidad que, como vemos, establece múltiples analogías con el libro como dispositivo en el que se imprime la subjetividad y se revela como exposición de sentido y escenario de resemantización. A lo largo del artículo, establezco que esta "escritura significante" que es el tatuaje supone contextualizar ese cuerpo, conquistarlo según nuestra experiencia en el mundo, por y para otros, es decir, trazarse en sí mismo el dibujo propio. Los ejemplos visitados, aunque abiertos a otras lecturas, muestran las correspondencias entre la impresión sobre la piel del sujeto y su experiencia en y del mundo, por lo que visualizan relaciones que no polarizan las jurisdicciones del cuerpo como objeto y las del cuerpo viviente, sino que sus facultades se extienden al cuerpo como lenguaje y significación.

En este texto, he planteado así una (re)apropiación del cuerpo a través del tatuaje similar al modo en que la tinta hace que las páginas se sometan a algún relato; pues es la tinta la que otorga sentido, contenido y causalidad -incluso ficción- a dichos soportes, sea el libro o el cuerpo, para extenderlos como dispositivos alejados de sus topografías materiales para ubicarlos como

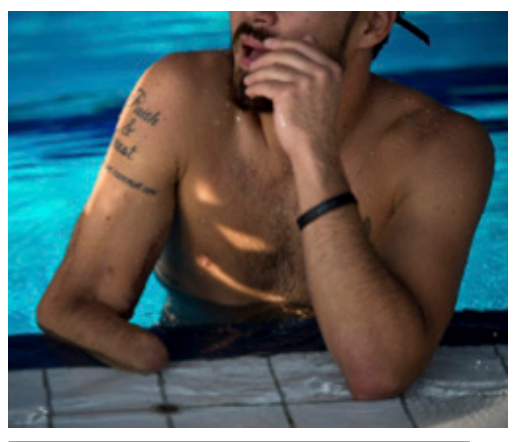

Figura 6. Fotografía del exmilitar Daniel Crane participando en los Invictus Games (2014) en Londres. Su tatuaje en el miembro amputado dice "Faith and trust in what we cannot see" (Fey confianza en aquello que no podemos ver), haciendo clara referencia a la ausencia de su antebrazo a la vez que a la inmaterialidad de la esperanza y de las creencias individuales. 
sucesos narrativos. Los resultados de este grabado en la carne es la presentación gráfica de una ausencia precisamente ubicada en la cosa que piensa y siente, como huella de aquello que afectivamente ha quedado como signo en efecto y figuración. Porque, como hemos visto, este diseño corporal nace de experiencias que el sujeto adopta para expresar su universo individual, para identificarse y hacerse visible -precisamente en su misma piel-, explicitándose tanto desde la diferencia como desde la pertenencia, pero subrayando siempre su unicidad como individuo (Sastre, 2011); ya que su vida es única y el tatuaje será la síntesis visual de cierta singularidad en tinta indeleble, un registro mnemotécnico permanente. Así como los libros están destinados a la preservación cultural que describen las historias de diferentes tiempos, el cuerpo diseñado es la conservación de las subjetividades del individuo. Si bien atestiguamos un momento en el que la gráfica ha ampliado sus particularidades expresivas a otros espacios privados y públicos, así como a diferentes utensilios, complementos y tecnología (Mínguez, 2012), esta gráfica caminante, permite el acceso a una imagen del sujeto que autogestiona sus discursos y reivindica el control del cuerpo expuesto. Por esta razón, expongo a lo largo del escrito que la piel, como las páginas de un libro, no es una frontera impermeable, que en y desde ella intercambiamos los mundos y nuestras historias. Se convierte en una región circulatoria en la que los mensajes transitan de un lado a otro, en movimiento y en relación para configurar, en ese trasegar, la operatividad de los signos en las superficies. Finalmente, es manifiesto que la extensión del presente artículo no puede abordar las heterogéneas dimensiones de la escritura sobre la piel, así como tampoco acotar de forma coherente el universo del libro o extender más las interesantísimas comunicaciones del cuerpo y el libro como mecanismos de ampliación de realidades. Sin embargo, al considerar el cuerpo como libro (des)plegado -reflejo de lo de adentro y de lo de afuera-, he tratado de atisbar un momento, en el que el que la piel escrita, esta superficie grafiada por un tatuaje, permite el diseño en tinta de una subjetividad en un afuera, la narración de sí mismo al exterior que corporiza las historias y visibiliza su sentir. 


\section{Referencias}

Candau, J. (2006). Antropología de la memoria. Buenos Aires: Nueva Visión.

Carvajal, J. (2014). El tatuaje como un espacio emblemático de las marcas. Trabajo de Grado para optar por el título de comunicador social. Facultad de Comunicación y lenguaje. Inédito. Bogotá: Pontificia Universidad Javeriana.

Corci, P.; Mayer, M. (1998). Biografía de la piel. Esbozo para una enciclopedia del tatuaje. Buenos Aires: Libros Perfil.

Derrida, J. (2011). El tocar, Jean-Luc Nancy. Buenos Aires: Amorrortu.

Esposito, R. (2016). Las personas y las cosas. Buenos Aires: Katz.

Esteban, M.L. (2004). Antropología del cuerpo. Género, itinerarios corporales, identidad y cambio. Barcelona: Bellaterra.

Ferrada, J. (2014). El cuerpo como arquitectura del sentido (Para una poética de la luz en la obra de Alfredo Jaar). Tesis para optar al grado de Doctor en Filosofía. Santiago de Chile: Universidad de Chile, Facultad de Artes.

Finol, J. E. (2014). "Antropo-Semiótica y Corposfera: Espacio, límites y fronteras del cuerpo." En Opción, vol. 30, núm. 74, mayo-agosto, pp. 154-171. Universidad del Zulia Maracaibo, Venezuela.

Foos, C. (2012). "Lo que el tatuaje escribe en el cuerpo. El tatuaje como signo". En Letras, $n^{\circ} 4$, pp.28-31. Conferencia pronunciada el espacio de Conferencias Introductorias al Psicoanálisis del NUCEP-Madrid el 10-10-2011.

García, R.; Guzmán, D. (s.f.). Escrito en el cuerpo. Gobierno de Santa Fe.

Garrido, C.D. (2010). "Cuando el recuerdo se hace piel: tatuarse para no olvidar". En las VI Jornadas de Sociología de la UNLP, pp. 1-18.Universidad Nacional de La Plata. Facultad de Humanidades y Ciencias de la Educación.

González García, A. (2013) "El tatuaje y la perforación en la construcción de la corporeidad". En Cultura de los
Cuidados. 17, $\mathrm{n}^{\circ} 37$, pp. 22-29. Recuperado en: http:// dx.doi.org/10.7184/cuid.2013.37.03

Haber, S.; Andrieu, B.; Molinier, P. (2007). Cuerpos dominados, cuerpos en ruptura. Buenos Aires: Nueva Visión.

Le Breton, D. (2002). La sociología del cuerpo. Buenos Aires: Nueva Visión.

Mangieri, R. (2014). Imagoletragrafía. Elementos de semiótica visual y teoría semiótica general. Mérida: Universidad de Los Andes.

Martínez Rossi, S. (2011). La piel como superficie simbólica. Procesos de transculturación en el arte contemporáneo. Madrid: Fondo de Cultura Económica.

Méndez, C. (2010). “Gráfica viva: aplicaciones de la imagen múltiple en el mundo contemporáneo". En Actas de Diseño 9. Facultad de Diseño y Comunicación. Buenos Aires: Universidad de Palermo. pp. 29-226. Recuperado en : https://fido.palermo.edu/servicios_ dyc/publicacionesdc/archivos/148_libro.pdf

Merleau-Ponty, M. (1993). Fenomenología de la percepción. Barcelona: Planeta-De Agostini.

Merleau-Ponty, M. (2006). Elogio de la filosofía. El lenguaje indirecto y las voces del silencio. Buenos Aires: Nueva Visión

Mínguez, H. (2012). Gráfica contemporánea. Del elogio de la materia a la gráfica intangible. Ciudad Juárez: Universidad Autónoma de Ciudad Juárez.

Nancy, J.L. (2003). Corpus. Madrid: Arena Libros.

Nancy, J.L. (2007). 58 indicios sobre el cuerpo. Extensión del alma. Buenos Aires: La Cebra.

Nancy, J.L. (2007). La representación prohibida. Buenos Aires: Amorrortu.

Richir, M. (2015). El cuerpo. Madrid: Brumaria.

Sastre, Asceneth (2011). "Cuerpos que narran: la práctica del tatuaje y el proceso de subjetivación". En Diversitas: Perspectivas en Psicología, vol. 7, núm. 1, enero-junio. Bogotá: Universidad de Santo Tomás, pp. 179-191

Velasco Maíllo, H. (2007). Cuerpo y espacio: símbolos, metáforas, representación y expresividad en las culturas. Madrid: Editorial Universitaria Ramón Areces. 